\title{
Synthesis of a Disulfide Cross-Linked DNA Triple Helix
}

\author{
Jay T. Goodwin1, Scott E. Osborne, Patrick C. Swanson² and Gary D. Glick* \\ Department of Chemistry \\ University of Michigan \\ Ann Arbor, Michigan 48109-1055 U.S.A.
}

Key Words: Disulfide cross-link, DNA triple helix

\begin{abstract}
An intramolecular DNA triple helix incorporating a disulfide cross-link has been synthesized. Potassium permanganate footprinting and UV melting analysis demonstrate that the cross-link increases the conformational stability of this novel triplex at physiological $\mathrm{pH}$ and $\left[\mathrm{Mg}^{2+}\right]$ relative to the unmodified sequence.
\end{abstract}

Molecular recognition of B-DNA through triple helix formation has provided the basis for construction of novel sequence-specific repressors of protein-DNA binding ${ }^{3}$ along with sequence-selective nucleases. ${ }^{4}$ To achieve greater specificity in these reactions, recent investigations have focused on elucidating the conformational and thermodynamic parameters that characterize this structural motif. ${ }^{5}$ These studies often employ sequences that fold intramolecularly, due to their enhanced stability and simplified stoichiometry relative to triplexes formed by the association of three independent DNA oligomers. ${ }^{6}$ While significant advances have been made in elucidating the properties of intramolecular triplexes, these efforts have been complicated by the conformational heterogeneity of some sequences near physiological $\mathrm{pH} .6 \mathrm{c}$ In particular, folding of canonical pyrimidine Hoogsteen hydrogen bonds, and dashes $=$ Watson-Crick base-pairing) requires protonation of the cytosine N-3 positions, and the Hoogsteen strand of such triplexes can dissociate from the major groove near $\mathrm{pH} 7.7,8$

Several approaches to stabilize the conformation of pyopupy triplexes have recently been described. These methods include the use of intercalating ligands covalently attached at the terminus of the Hoogsteen strand, $9 \mathrm{a}$ photochemical crosslinking of the triplex, ${ }^{\text {9a-c }}$ and modified bases that bind either by intercalating into the Watson-Crick duplex or by mimicking the protonated state of the Hoogsteen cytosine. 10 We have recently found that incorporation of disulfide cross-links into nucleic acids can stabilize DNA and RNA secondary structures without imparting structural perturbations. ${ }^{11 a-d}$ Here we present the extension of this methodology to stabilize an intramolecular py•pu-py DNA triple helix against thermal and $\mathrm{pH}$-induced denaturation under physiologically relevant conditions.

In previous studies, we incorporated disulfide cross-links

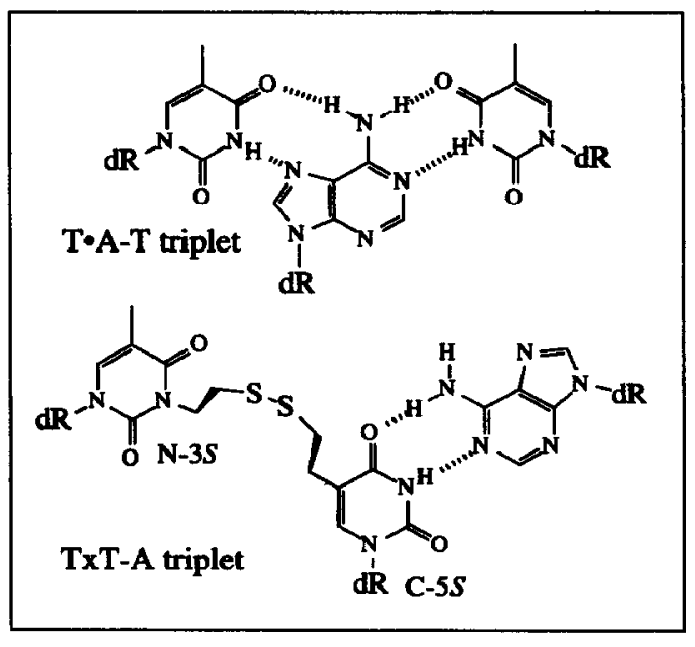
in DNA by bridging the N-3 positions of a terminal T-T 
mismatch with mercaptoethyl linkers. ${ }^{11 a-d}$ However, this strategy is not applicable to cross-link a triplex structure because the thymidine $\mathrm{N}-3$ positions of a $\mathrm{T} \cdot \mathrm{A}-\mathrm{T}$ triplet are involved in hydrogen bonding to the purine strand. $11 \mathrm{~b}, \mathrm{c}$ While a T•T-A triplet brings the two thymidines into proximity, the N-3 of the purine strand thymidine remains basepaired to the opposing 2'-deoxyadenosine. In a T-T-A triplet, however, the C-5 position of the purine strand thymidine faces the Hoogsteen thymidine N-3 in the major groove. Thus, synthesis of a DNA oligomer containing N3-thioethylthymidine $(\mathrm{N}-3 S)^{11 \mathrm{c}}$ at the $3^{\prime}$-end of the Hoogsteen strand and $\mathrm{C}-5$ thioethyl-2'-deoxyuridine (C-5S) ${ }^{12}$ at the opposing site on the Watson-Crick purine strand will position the thiols to form a disulfide cross-link.

We selected a 34-nucleotide long sequence designed to fold intramolecularly into a DNA triple helix for study due to characterization of a related triple helix by Häner and Dervan. ${ }^{6 \mathrm{~d}}$ The DNA sequence incorporating N-3S and C5S was prepared on a $1 \mu$ mole scale using a Millipore Expedite synthesizer with the thiol-modified bases protected as t-butyl mixed disulfides (Figure 1).13 In preliminary experiments we compared triplex formation of unmodified sequence 1 and $t$-butyl disulfide-modified sequence 2 as a function of $\mathrm{pH}$ to determine the optimal conditions for oxidative cross-linking. ${ }^{11 \mathrm{~d}}$ At $\mathrm{pH} 6$ in phosphate-buffered saline (PBS) containing $0.5 \mathrm{mM} \mathrm{MgCl}_{2},{ }^{14}$ the $\mathrm{CD}$ spectra of both 1 and 2 show negative ellipticities of comparable intensity at $213 \mathrm{~nm}$, characteristic of DNA triplexes. ${ }^{15}$ This result suggests that the linkers do not interfere with binding of the Hoogsteen strand in the duplex major groove. Titrating to $\mathrm{pH} \mathrm{8,} \mathrm{the} \mathrm{optimal} \mathrm{pH}$ for the oxidation reaction, $11 \mathrm{~d}$ causes both triplexes to unfold to hairpin structures, resulting in positive ellipticities at $213 \mathrm{~nm}$. Even in the presence of higher $\left[\mathrm{Mg}^{2+}\right]$ (e.g., $5 \mathrm{mM}$ ) which is known to stabilize DNA triplexes, 6,16 the CD spectra indicate that at $\mathrm{pH} 8$ the Hoogsteen strands of 1 and 2 are not bound in the major groove. Therefore, as a compromise between optimal conditions for cross-linking and triplex formation, we performed the cross-linking reaction in PBS containing $5 \mathrm{mM} \mathrm{MgCl}_{2}$ at $\mathrm{pH} 7$. Following deprotection of 2 with dithiothreitol, 12 air oxidation for 24 hours provided a near quantitative conversion to 3 as judged by reversed-phase HPLC.

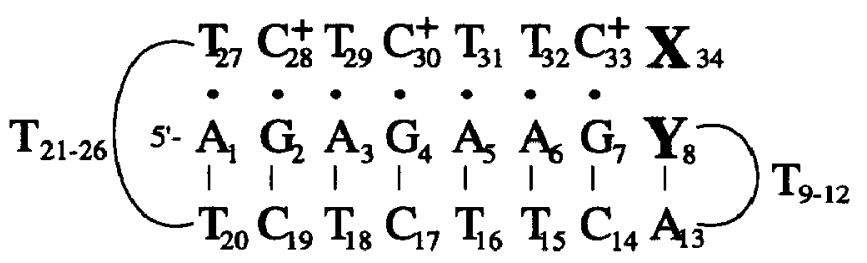

$$
\begin{aligned}
& \text { 1: } \mathbf{X}, Y=T \\
& \text { 2: } \mathbf{X}=\mathbf{N}-3 S S-t-\mathrm{Bu} \\
& \mathbf{Y}=\mathbf{C}-5 S S-t-B u \\
& \text { 3: } \begin{aligned}
X & =\mathbf{N}-35 \\
Y & =\mathbf{C}-55
\end{aligned} \mid \text { disulnde }
\end{aligned}
$$

Figure 1. Sequence of the disulfide cross-linked intramolecular DNA triple helix. After folding to a triple helix the alkylthiol tethers are positioned to form a disulfide bond between the 3 -terminus and the Watson-Crick purine strand.

Potassium permanganate footprinting provides a sensitive assay for involvement of the Hoogsteen strands of 1 and 3 in triplex formation. 60,17 Extensive permanganate reactivity is observed for 1 at both $\mathrm{pH} 6.0$ and 7.4 in PBS containing $0.5 \mathrm{mM} \mathrm{Mg}^{2+}$, with reactivity of the thymines increasing with proximity to the 3'-terminus (Figure $2 \mathrm{~A}$ ). Even with $\left[\mathrm{Mg}^{2+}\right]=5.0 \mathrm{mM}$, the thymine bases on the Hoogsteen strand of 1 are reactive at pH 7.4 (Figure 2B). These results are consistent with fraying of the Hoogsteen strand out of the duplex major groove, presumably concomitant with deprotonation of the Hoogsteen cytosine residues. By contrast, the corresponding thymine bases of 3 remain significantly protected even at $\mathrm{pH} 7.4$.

The UV melting profiles of the unmodified sequence 1 are biphasic where the first transition at $\sim 15{ }^{\circ} \mathrm{C}$ corresponds to dissociation of the Hoogsteen strand from the hairpin duplex, and the second transition at $64^{\circ} \mathrm{C}$ represents melting of the duplex to a single-stranded coil. By contrast, 3 exhibits monophasic thermal denaturation, 
with a $T_{\mathrm{m}}$ of $52{ }^{\circ} \mathrm{C}$; the disulfide cross-link stabilizes binding of the third strand by $-40{ }^{\circ} \mathrm{C}$ relative to 1 . The relatively minor loss of protection for 3 towards $\mathrm{KMnO}_{4}$ at higher $\mathrm{pH}$, combined with the increased thermal stability suggests that the cross-link effectively locks the third strand into the major groove.

(A)

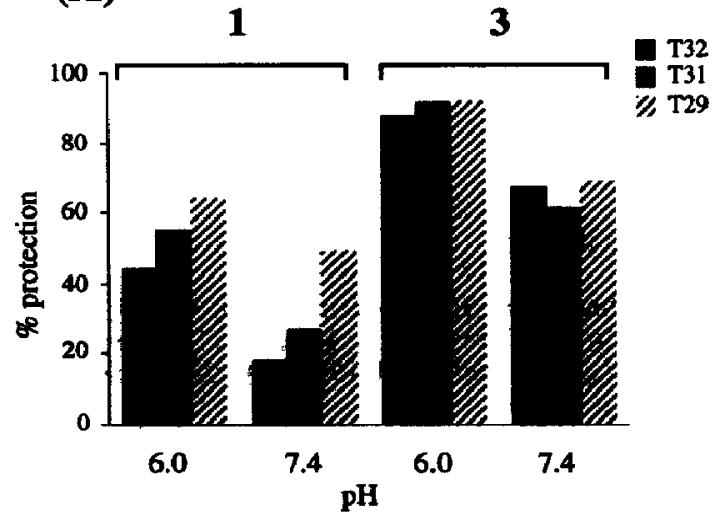

(B)

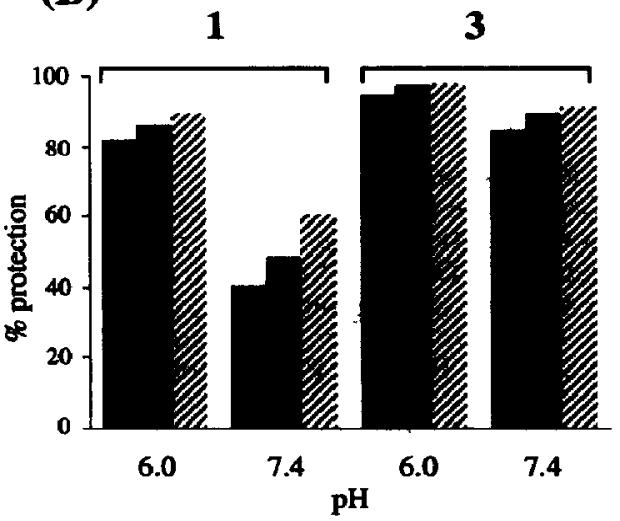

Figure 2. $\mathrm{KMnO}_{4}$ footprinting assay. ${ }^{6 d, 18}$ The extent of protection for the Hoogsteen thymines T32, T31, and T29 were determined by comparison with the reactivity of loop thymine T24 as an internal standard. The presence of the disulfide cross-link does not considerably alter the pattern of $\mathrm{KMnO}_{4}$ reactivity for the Hoogsteen strand relative to 1, suggesting that it does not significantly disrupt or distort the native triplex geometry. ${ }^{19}$ Results similar to those for 1 are observed for the parent sequence.6d (A) $0.5 \mathrm{mM} \mathrm{Mg}^{2+}$ and (B) $5.0 \mathrm{mM} \mathrm{Mg} \mathrm{M}^{2+}$.

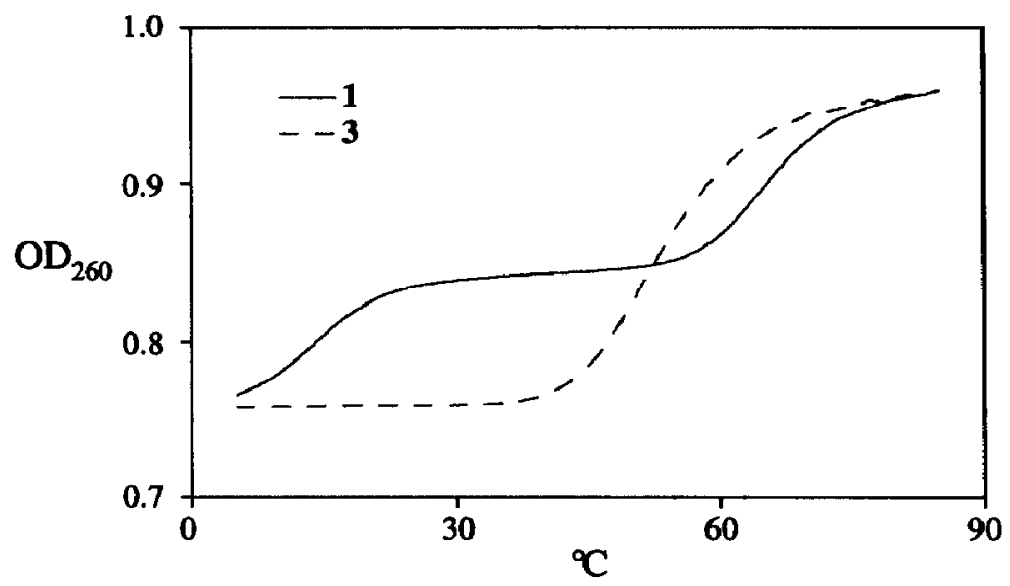

Figure 3. UV thermal denaturation. Melting curves were obtained at a rate of $0.5{ }^{\circ} \mathrm{C} / \mathrm{min}$ in PBS, $\mathrm{pH}$ 7.4 , containing $0.5 \mathrm{mM} \mathrm{Mg}^{2+}$. The melting profile for the parent sequence $6 \mathrm{~d}$ is similar to that observed for 1 (data not shown). 
In conclusion, we have demonstrated that the site-specific incorporation of a disulfide cross-link into an intramolecular DNA triple helix provides conformational stability towards $\mathrm{pH}$-induced and thermal denaturation. Preliminary NMR experiments indicate that 3 remains conformationally homogeneous at pH 7.4 and $37^{\circ} \mathrm{C}$. Other disulfide linkers, of greater and shorter length, are currently being examined for their influence upon triplex stability. ${ }^{12}$ This research extends the applicability of our cross-linking methodology from hairpins and duplexes to a higher order DNA conformation, and affords the opportunity to investigate further the conformational, dynamic, and thermodynamic properties of py॰pu-py triplexes under more physiologically relevant conditions.

\section{REFERENCES AND Footnotes}

1. NIH Poptiloctoral Fellow.

2. NIH M plecular Biophysics Predoctoral Fellow.

3. Maher, L.J., III BioEssays 1992, 14, 807, and references therein.

4. Moser, H.E.; Dervan, P.B. Science 1987, 238, 645.

5. For example: (a) Ragjunathan, G.; Miles, H.T.; Sasisekhapan, V. Biochemistry 1993, 32 , 455. (b) Roug6e, M.; Faucon, B.; Mergny, J.L.; Baroelo, F.; Giovannangeli, C.; Garestier. T.; Fildene, C. Ebochemistry 1992, 31,9269. (c) Roberts, R.W.; Crothers, D.M. Proc. Natl. Acad. Sct. UhA 1992,88, 9397. (d) Pilch, D.S.; Brousseau, R.; Shifer, R.H. Nucleic Acids Res. 1990, 18, 5743.

6. (a) Durand, M.; Peloille, S.; Thuong, N.T.; Maurizot, J.C. Biochemistry 1992, 31, 9197. (b) Wang, E.; Malek, S.; Feigon, J. Biochemistry 1992, 31, 836, and references therein. (c) Sklenar, V.; Feigon, J. Nature 1990, 345, 836. (d) Häner, R.; Dervan, P.B. Biochemistry 1990, 29, 9761.

7. Cytosine has a $\mathrm{pK}$ a of 4.5; see Saenger, $W$. Principles of Nucleic Acid Structure; Springer-Verlag: New York, 1984; $\mathrm{p} 108$. Although $\mathrm{p} K_{\mathrm{a}}$-values of the cytosines in the Hoogsteen strand are shifted upward by 2-3 pH units ${ }^{8}$ significant conformational beterogeneity is still observed for some triplexes at or near physiological pH. $6 \mathbf{c}, 10 \mathbf{a}$

8. Völker, J.; Botes, D.P.; Lindsey, G.G.; Klump, H.H. J. Mol. Biol. 1993, 230, 1278.

9. (a) Praseuth, D.; Perrouault, L.; Le Doan, T.; Chassignol, M.; Thuong, N.; Helène, C. Proc. Natl. Acad. Sci. USA 1988, 85, 1349. (b) Grigoriev, M.; Praseuth, D.; Guieysse, A.L.; Robin, P.; Thuong, N.T.; Helène, C.; Harel-Bellan, A. Proc. Natl. Acad. Sci. USA 1993, 90, 3501. (c) Le Doan, T.; Perrouault, L.; Praseuth, D.; Habhoub, N.; Decout, J.-L.; Thuong, N.T.; Lhomme, J.; Hélene, C. Nucleic Acids Res. 1987, 15, 7749.

10. (a) Radhakrishnan, I.; Patel, D.J.; Priestley, E.S.; Nash, H.W.; Dervan, P.B. Biochemistry 1993, 32 , 11228. (b) Koshlap, K.M.; Gillespie, P.; Dervan, P.B.; Feigon, J. J. Am. Chem. Soc. 1993, 115, 7908. (c) Griffin, L.C.; Kiessling, L.L.; Beal, P.A.; Gillespie, P.; Dervan, P.B. J. Am. Chem. Soc. 1992, 114, 7976. (d) Koh, J.S.; Dervan, P.B. J. Am. Chem. Soc. 1992, 114, 1470. (e) Krawczyk, S.H.; Milligan, J.F.; Wadwani, S.; Moulds, C.; Froehler, B.C.; Matteucci, M.D. Proc. Natl. Acad. Sci. USA 1992, 89, 3761 .

11. (a) Wang, H.; Osborne, S.E.; Zuiderweg, E.R.P.; Glick, G.D. J. Am. Chem. Soc. manuscript in press. (b) Goodwin, J.T.; Glick, G.D. Tetrahedron Lett. 1994, 35,1647. (c) Glick, G.D.; Osborne, S.E.; Knitt, D.E.; Marino, J.P., Jr. J. Am. Chem. Soc. 1992, 114, 5447. (d) Glick, G.D. J. Org. Chem. 1991, 56, 6746. For other examples of disulfide cross-links in nucleic acids, see: (e) Lipsett, M.N. Cold Spring Harbor Symp. Quant. Biol. 1966, 31, 449. (f) Carbon, J.A.; Hung, L.; Jones, D.S. Proc. Natl. Acad. Sci. USA 1965, 53, 979. (g) Wolfe, S.A.; Verdine, G.L. J. Am. Chem. Soc. 1993, 115, 12585. (h) Ferentz, A.E.; Keating, T.A.; Verdine, G.L. J. Am. Chem. Soc. 1993, 115, 9006, and references therein. (i) Milton, J.; Connolly, B.A.; Nikiforov, T.T.; Cosstick, R. J. Chem. Soc., Chem. Commun. 1993, 780.

12. Goodwin, J.T.; Glick, G.D. Tetrahedron Lett. 1993, 34, 5549.

13. Composition of the modified DNA oligomers was verified by enzymatic degradation.

14. Bremel, R.D.; Weber, A. Biochim. Biophys. Acta 1975, 376, 366.

15. (a) Kan, L.S.; Callahan, D.H.; Trapane, T.L.; Miller, P.S.; Ts'o, P.O.P. J. Biomol. Struct. Dyn. 1991, 8, 911. (b) Manzini, G.; Xodo, L.E.; Gasparotto, D.; Quadrifoglio, F.; van der Marel, G.A.; van Boom, J.H. J. Mol. Biol. 1990, $213,833$.

16. In PBS precipitation of $\mathrm{Mg}^{2+}$ salts occurs for $\left[\mathrm{Mg}^{2+}\right]>5 \mathrm{mM}$ and $\mathrm{pH}>7$ precluding studies at higher divalent ion concentrations.

17. Base-paired thymines stack onto adjacent bases, sterically inhibiting reactivity of the C5-C6 double bond towards dihydroxylation by $\mathrm{KMnO}_{4}$.

18. Swanson, P.C.; Glick, G.D. BioMed. Chem. Lett. 1993, 3, 2117.

19. These results are consistent with $C D, U V$, and NMR studies of 1 and 3 ; manuscript in preparation. 